\title{
Commentary: Calcium in the pathomechanism of amyotrophic lateral sclerosis - Taking center stage?
}

\author{
Valéria Meszlényi ${ }^{1}$, Roland Patai ${ }^{2}$, Bernát Nógrádi ${ }^{1}$, József I. Engelhardt ${ }^{3}$, László Siklós ${ }^{2 *}$ \\ ${ }^{\prime}$ Foundation for the Future of Biomedical Sciences in Szeged, Pálfy u. 52/d, H-6725 Szeged, Hungary \\ ${ }^{2}$ Institute of Biophysics, Biological Research Center of the Hungarian Academy of Sciences, Temesvári krt. 62, H-6726 Szeged, Hungary \\ ${ }^{3}$ Department of Neurology, University of Szeged, Semmelweis u. 6, H-6725 Szeged, Hungary
}

\section{Article Info}

\section{Article Notes}

Received: February 20, 2017

Accepted: April 04, 2017

\section{*Correspondence:}

László Siklós Ph.D., D.Sc.

Institute of Biophysics

Biological Research Center of the Hungarian Academy of

Sciences, 6701 Szeged, P.O. Box 521, Hungary

Telephone: +36-62-599611

Fax: $+36-62-433133$

Email: siklos.laszlo@brc.mta.hu

() 2017 Siklós L. This article is distributed under the terms of the Creative Commons Attribution 4.0 International License

\section{Keywords}

Amyotrophic lateral sclerosis

Calcium

Calcium buffering

Neurodegeneration

Motor neuron

Electron microscopy

\section{ABSTRACT}

Amyotrophic lateral sclerosis is a rare and fatal neurodegenerative disorder characterized by the progressive loss of motor neurons in the central nervous system and neuromuscular junctions in the periphery. The pathomechanism behind the disease, except from some familiar cases associated with genetic mutations, remains unclear, however, numerous mechanisms contributing to the disease have already been disclosed. The key components are the oxidative stress, excitotoxicity, mitochondrial dysfunctions and inflammatory processes. In addition, increased intracellular calcium, which is another identified pathological event, could merge these individual toxic mechanisms into a single, escalating and self-perpetuating cycle of neuronal degeneration. Our previous results suggest that calcium homeostasis might be preserved by modulating the transmembrane calcium flux with therapeutic compounds or via altering the calcium binding protein content to maintain an enhanced calcium buffer capacity. The scope of this commentary is to accentuate the reciprocal calcium dependence of the pathological events associated with amyotrophic lateral sclerosis and to discuss possible therapeutic strategies based on the restoration of calcium homeostasis.

\section{Introduction}

French neurologist, Jean Martin Charcot, was the first who defined amyotrophic lateral sclerosis (ALS) as „la sclérose latérale amiotrophique” which is a French expression for a pathological manifestation of the disease. Pioneering work of Professor Charcot was the autopsy report of the scar tissue in the anterolateral fasciculus of the spinal cord which manifested as spasticity and paralysis in the patients ${ }^{1}$. Nowadays amyotrophic lateral sclerosis is known as a non-cell autonomous ${ }^{2}$, multifactorial $^{3}$ and multisystem disease ${ }^{4}$, however its exact origin and all the details of the development of the disorder, relentlessly leading to death, are still unclear. Several pathophysiological processes contributing to the progression of the disease have been disclosed in the last five decades, for instance genetic mutations in more than a dozen of genes $^{5}$, excitotoxicity ${ }^{6}$, oxidative stress ${ }^{7}$, immune/inflammatory processes $^{8}$, mitochondrial dysfunctions ${ }^{9}$ and disruption in calcium homeostasis ${ }^{10}$. Significance of calcium ions in different physiological and pathological conditions is a well-known phenomenon, since it has got a prominent biological property in reversible complex formations ${ }^{11}$ and second messenger function. As a rule in biochemical reactions, a limited concentration range characterizes the optimal conditions of the calcium-mediated processes: either too low or too high concentration values are irreconcilable with life. At low concentration values, the vital 
role of calcium was first demonstrated on isolated hearts ${ }^{12}$, reported by Sidney Ringer more than 130 years ago. At the other end of the concentration range, excess elevation in the intracellular calcium might lead to cell death ${ }^{13}$. Focusing on the state of the art concept of calcium mediated neuronal degeneration, in a recent manuscript, which appeared in the special issue of Biochemical and Biophysical Research Communications devoted to Neurodegeneration, we discussed the possible central role of the elevated calcium level in the pathomechanism of ALS ${ }^{14}$. In this commentary, we would like to corroborate that hypothesis with recent studies, furthermore, our neuroprotective trials and descriptive contribution to this special scientific field are also introduced.

\section{Reciprocal calcium mediated processes in the pathomechanism of ALS}

Involvement of elevated calcium concentration has been observed in chronic neurodegenerative diseases for instance in Alzheimer's disease ${ }^{15}$, Parkinson's disease ${ }^{16}$, Huntington's disease ${ }^{17}$ and $\mathrm{ALS}^{18}$, furthermore, role of elevated calcium level was confirmed in acute neuronal lesions, as well ${ }^{19}$. Interestingly, most of the known factors of pathological processes are capable to interfere with the calcium homeostasis. Thus, although increased intracellular calcium might be located downstream within the complex pathomechanism of ALS, impaired calcium homeostasis is considered a final common pathway leading to injury of motor neurons through a calcium-dependent positive feedback loop. This is further supported by the recent observation that elevated calcium acts as a driver of transactive response DNA binding protein (TDP-43) mediated neuronal toxicity ${ }^{20}$, because TDP-43 was identified as a main component of the cytoplasmic inclusions of the neurons in the majority of ALS patients ${ }^{21}$.

Excitotoxicity is a major pathological event in a wide variety of degeneration ${ }^{22}$, moreover, its crucial role in ALS was also supported by documenting a two-fold increase in the glutamate level in the sera ${ }^{23}$ and cerebrospinal fluid ${ }^{24}$ of ALS patients. Molecular basis of this glutamate elevation might be based on a reduced number of excitatory amino acid transporter 2 , since this receptor is responsible for a swift reuptake of glutamate ${ }^{25}$. In view of the fact that specific alterations in the subunit composition of the $\alpha$-amino-3-hydroxy-5-methyl-4-isoxazolepropionic acid (AMPA) glutamate receptors, namely, reduced number of the glutamate receptor 2 (GluR2) subunit was documented in ALS patients, which makes AMPA receptors permeable to calcium, the increased glutamate level may lead to an excess calcium influx and amplification of excitotoxicity ${ }^{26}$. Another well-characterized pathological pathway in ALS is a reactive oxygen species (ROS) mediated degeneration ${ }^{27}$, partially due to the gain of function mutation in the $\mathrm{Cu}$ / Zn superoxide dismutase enzyme (SOD1) observed in a subset of the patients ${ }^{28}$. Importantly, elevated calcium may induce conformational change of wild type SOD1 which facilitates its amorphous aggregation ${ }^{29}$, thus contributes to the oxidative stress ${ }^{30}$. These data accentuate the role of calcium-mediated protein misfolding also in nonSOD1, sporadic ALS ${ }^{31}$. ROS may change plasma membrane properties, target membrane embedded ion channels ${ }^{32}$, which may result in increased activity of $P / Q$ type voltage gated calcium channels ${ }^{33}$, and a consequent increase of intracellular calcium. Increased cytosolic calcium may further elevate its intracellular level by impairing endoplasmic reticular calcium buffers ${ }^{34}$, furthermore, may augment mitochondrial ROS production ${ }^{35}$. Since the major victims are the motor neurons in ALS, when injured, they signal to neighboring microglia, the resident macrophages of the nervous system. This signal could be chemokine ligand 2 (CCL2) $^{36}$, or other signaling molecules, yet to be identified. Microglia are equipped with the appropriate receptors and showed activation pattern in the same time frame as the expression of CCL2 by motor neurons after axonal transection ${ }^{36}$. Microglial activation was directly visualized by $\left[{ }^{11} \mathrm{C}\right](\mathrm{R})-\mathrm{PK} 11195$ positron emission tomography in the central nervous system of ALS patients ${ }^{37}$. Activated microglia, by releasing peroxynitrite, may induce membrane perturbations of the neighboring cells, and are capable to inhibit the function of membrane proteins, like glutamate transporters ${ }^{38}$, contributing to elevated glutamate levels and excitotoxicity. Furthermore, they can trigger a phenotypic transformation of astrocytes ${ }^{39}$, thus mount a full-blown cellular immune response. Besides cellular immunity, recent observations suggest that humoral immunity has a crucial role in disease progression by documenting the presence of more than 20 ALS specific antibodies in the sera of ALS patients ${ }^{40}$. ALS antibodies may also interact with L-type ${ }^{41}$, or N-/P/Q-type calcium channels ${ }^{42}$, as well, resulting in increased intracellular calcium in a motor neuron cell line ${ }^{43}$. The first direct evidence of increased calcium level paralleled with mitochondrial disruption in the pathology of ALS is based on electron microscopic observation of neuromuscular synapses in muscle biopsies obtained from ALS patients ${ }^{44}$. These findings got further support from transgenic animal model of ALS, based on SOD1 G93A mutation, where identical morphological changes and increased calcium could be observed not only in the motor axon terminals, but in the spinal motor neurons, as well ${ }^{45}$. These observations suggest, that while the pathomechanism is rather complex in ALS, calcium elevation may be a key component of the pathogenesis, thus neuroprotective trials should focus on this aspect of the disease.

Potential therapeutic possibilities based on the alleviation of calcium burden

Since sustained disruptions in the mechanism of 
physiological calcium homeostasis trigger malicious changes in neuronal functions, furthermore, induce apoptotic and other death-related signaling pathways, stabilization of such ionic balance might be a promising therapeutic possibility. Hints for such approaches might be obtained from the observations that not all neuronal populations are equally susceptible during the disease, namely, the oculomotor and the Onufrowicz nucleus are considered to be resistant regions in $\mathrm{ALS}^{46}$. The different resistance of these cells might be based on their unique properties, such as cell size or axonal length, size of the motor unit, network connections, etc, or special calcium homeostasis. Besides the number and composition of the ion channels in their plasma membranes, another relevant factor in shaping cellular calcium homeostasis is related to their calcium buffer capacity. The main component of the calcium buffersin thecytosolis comprised of calcium binding proteins with EF-hand motifs ${ }^{47}$. Indeed, systematic studies of brain and spinal cord autopsy samples from ALS patients led to the conclusion that some of these proteins, such as calbindin- $\mathrm{D}_{28 \mathrm{k}}$ or parvalbumin might be used as marker of resistant cell types ${ }^{48}$. Based on such observations, in vitro and in vivo studies showed that elevation of parvalbumin or calbindin- $\mathrm{D}_{28 \mathrm{k}}$ level in vulnerable cells provide an enhanced resistance against calcium-mediated acute injury $^{49,50,51}$. In a chronic motoneuron degeneration model, based on transgenic mutant SOD1 animals, by creating double transgenic mice with upregulated parvalbumin, significant neuroprotection could also be achieved, but the progression of the disease could not be stopped ${ }^{52}$. Also in the mSOD1 transgenic mouse strain, an alternative way to reduce calcium burden of motor neurons has been tried by applying AMPA receptor antagonist, talampanel ${ }^{53}$ During these experiments, calcium increase in spinal motor neurons of transgenic animals could be successfully prevented only if the treatment was started prior to the appearance of the symptoms of the disease ${ }^{53}$. Considering the universal role of calcium in the pathomechanism, the meager results of protective attempts in the chronic ALS models were unexpected. The reason behind the moderate success might be based on the fact, that calcium buffer capacity merely prolongs the proper homeostasis but loses its effectiveness due to the inevitable saturation of the buffer system. Furthermore, if the therapeutic attempt with AMPA receptor antagonists is started too late, the dialog between the glial cells and motor neurons might have switched from neuroprotective to neurotoxic mode ${ }^{8}$, which phase might be identified in the temporal trends of oxidation, respiration, and calcium regulation ${ }^{54}$.

\section{Acknowledgement}

This work was financially supported by
GINOP-2.3.2-15-2016-00001 and the

GINOP-2.3.2-15-2016-00034 programs. Our work was also supported by the "Foundation for the Future of Biomedical Sciences in Szeged" program with the financial aid of the Ministry of Human Capacities (34232-3/2016/INTFIN).

\section{References}

1. Charcot JM, Joffroy A. Deux cas d'atrophie musculaire progressive avec lesion de la substance grise et des faisceaux antéro-latéraux de la moelle épinière. Arch Physiol Neurol Path. 1869; 2: 744-754.

2. Boillée S, Vande Velde C, Cleveland DW. ALS: a disease of motor neurons and their nonneuronal neighbors. Neuron. 2006; 52: 39-59.

3. Vucic S, Rothstein JD, Kiernan MC. Advances in treating amyotrophic lateral sclerosis insights from pathophysiological studies. Trends Neurosci. 2014; 37: 433-442.

4. Swinnen B, Robberecht $\mathrm{W}$. The phenotypic variability of amyotrophic lateral sclerosis. Nature Rev Neurol. 2014; 10: 661-670.

5. Beleza Meireles A, Al-Chalabi A. Genetic studies of amyotrophic lateral sclerosis Controversies and perspectives. Amyotroph Lat Scler. 2009; 10: $1-14$.

6. Choi DW. Amyotrophic lateral sclerosis and glutamate too much of a good thing. New Eng J Med. 1992; 326: 1493-1495.

7. Barber SC, Shaw PJ. Oxidative stress in ALS Key role in motor neuron injury and therapeutic target. Free Rad Biol Med. 2010; 48: 629-641.

8. Hooten KG, Beers DR, Zhao W, et al. Protective and toxic neuroinflammation in amyotrophic lateral sclerosis. Neurotherapeutics. 2015; 12: 364-375.

9. Carrì MT, D’Ambrosi N, Cozzolino M. Pathways to mitochondrial dysfunction in ALS pathogenesis. Biochem Biophys Res Commun. 2017; 483: 1187-1193.

10. Grosskreutz J, Van Den Bosch L, Keller BU. Calcium dysregulation in amyotrophic lateral sclerosis. Cell Calcium. 2010; 47: 165-174.

11. Carafoli E. Calcium signaling a tale for all seasons. Proc Natl Acad Sci USA. 2002; 99: 1115-1122.

12. Ringer S. A further contribution regarding the influence of the different constituents of the blood on the contraction of the heart. J Physiol. 1883; 4: 29-42.

13. Berridge MJ, Bootman MD, Lipp P. Calcium a life and death signal. Nature. 1998; 395: 645-648.

14. Patai R, Nógrádi B, Engelhardt JI, et al. Calcium in the pathomechanism of amyotrophic lateral sclerosis Taking center stage. Biochem Biophys Res Commun. 2017; 483: 1031-1039.

15. Popugaeva E, Pchitskaya E, Bezprozvanny I. Dysregulation of neuronal calcium homeostasis in Alzheimer's disease - A therapeutic opportunity. Biochem Biophys Res Commun. 2017; 483: 998-1004.

16. Surmeier DJ, Schumacker PT, Guzman JD, et al. Calcium and Parkinson's disease. Biochem Biophys Res Commun. 2017; 483: 1013-1019.

17. Raymond LA. Striatal synaptic dysfunction and altered calcium regulation in Huntington disease. Biochem Biophys Res Commun. 2017; 483: 1051-1062.

18. Appel SH, Smith RG, Alexianu M, et al. Increased intracellular calcium triggered by immune mechanisms in amyotrophic lateral sclerosis. Clin Neurosci. 1996; 3: 368-374.

19. Mandolesi G, Madeddu F, Bozzi Y, et al. Acute physiological response of mammalian central neurons to axotomy: ionic regulation and electrical activity. FASEB J. 2004; 18: 1934-1936.

20. Aggad D, Vérièpe J, Tauffenberger $A$, et al. TDP-43 toxicity proceeds via calcium dysregulation and necrosis in aging Caenorhabditis elegans motor neurons. J Neurosci. 2014; 34: 12093-12103. 
21. Kiernan MC, Vucic S, Cheah BC, et al. Amyotrophic lateral sclerosis. Lancet. 2011; 377: 942-955.

22. Rothman SM, Olney JW. Excitotoxicity and the NMDA receptor. Trends Neurosci. 1987; 10: 299-302.

23. Plaitakis A, Caroscio JT. Abnormal glutamate metabolism in amyotrophic lateral sclerosis. Ann Neurol. 1987; 22: 575-579.

24. Rothstein JD, Kuncl RW, Chaudry V, et al. Excitatory amino acids in amyotrophic lateral sclerosis. Ann Neurol. 1991; 30: 224-225.

25. Rothstein JD, Van Kammen M, Levey AI, et al. Selective loss of glial glutamate transporter GLT-1 in amyotrophic lateral sclerosis. Ann Neurol. 1995; 38: 73-84.

26. Williams TL, Day NC, Ince PG, et al. Calcium-permeable alpha-amino3-hydroxy-5-methyl-4-isoxazole propionic acid receptors a molecular determinant of selective vulnerability in amyotrophic lateral sclerosis. Ann Neurol. 1997; 42: 200-207.

27. Ferrante RJ, Browne SE, Shinobu LA, et al. Evidence of increased oxidative damage in both sporadic and familial amyotrophic lateral sclerosis. J Neurochem. 1997; 69: 2064-2074.

28. Rosen DR, Siddique T, Patterson D, et al. Mutations in $\mathrm{Cu} / \mathrm{Zn}$ superoxide dismutase gene are associated with familial amyotrophic lateral sclerosis. Nature. 1993; 362: 59-62.

29. Leal SS, Cardoso I, Valentine JS, et al. Calcium ions promote superoxide dismutase 1 (SOD1) aggregation into non-fibrillar amyloid A link to toxic effects of calcium overload in amyloid lateral sclerosis (ALS). J Biol Chem. 2013; 288: 25219-25228.

30. Carrì MT, Cozzolino M. SOD1 and mitochondria in ALS a dangerous liaison. J Bioenerg Biomembr. 2011; 43: 593-599.

31. Carrì MT, Valle $\mathrm{C}$, Bozzo $\mathrm{F}$, et al. Oxidative stress and mitochondrial damage: importance in non-SOD1 ALS. Front Cell Neurosci. 2015; 9: Article41.

32. Annunziato L, Pannaccione A, Cataldi M, et al. Modulation of ionic channels by reactive oxygen and nitrogen species a pathophysiological role in brain aging. Neurobiol Aging. 2002; 23: 819-834.

33. Li A, Ségui J, Heinemann SH, et al. Oxidation regulates cloned neuronal voltage-dependent $\mathrm{Ca} 2+$ channels expressed in Xenopus oocytes. J Neurosci. 1998; 18: 6740-6747.

34. Kiselyov K, Muallem S. ROS and intracellular ion channels. Cell Calcium. 2016; 60: 108-114.

35. Dykens JA. Isolated cerebral and cerebellar mitochondria produce free radicals when exposed to elevated $\mathrm{Ca}^{2+}$ and $\mathrm{Na}^{+}$: Implications for neurodegeneration. J Neurochem. 1994; 63: 584-591.

36. Paizs M, Patai R, Engelhardt JI, et al. Axotomy leads to reduced calcium increase and earlier termination of CCL2 release in spinal motoneurons with upregulated parvalbumin followed by decreased neighboring microglial activation. CNS \& Neurol Disord - Drug Targets. 2017; 16: xx-xx (in press).

37. Turner MR, Cagnin A, Turkheimer FE, et al. Evidence for widespread cerebral microglial activation in amyotrophic lateral sclerosis: an [11C](R)-PK11195 positron emission tomography study. Neurobiol Dis. 2004; 15: 601-609.

38. Trotti D, Rossi D, Gjesdal O, et al. Peroxynitrite inhibits glutamate transporter subtypes. J Biol Chem. 1996; 271: 5976-5979.
39. Cassina P, Peluffo H, Pehar M, et al. Peroxynitrite triggers a phenotypic transformation in spinal cord astrocytes that induces motor neuron apoptosis. J Neurosci Res. 2002; 67: 21-29.

40. May C, Nordhoff E, Casjens S, et al. Highly immunoreactive IgG antibodies directed against a set of twenty human proteins in the sera of patients with amyotrophic lateral sclerosis identified by protein array. Plos One. 2014; 9: e89596.

41. Smith RG, Hamilton S, Hofmann F, et al. Serum antibodies to L-type calcium channels in patients with amyotrophic lateral sclerosis. New Eng J Med. 1992; 327: 1721-1728.

42. Llinás R, Sugimori M, Cherksey BD, et al. IgG from amyotrophic lateral sclerosis patients increases current through P-type calcium channels in mammalian cerebellar Purkinje cells and isolated channel protein in lipid bilayer. Proc Natl Acad Sci USA. 1993; 90: 11743-11747.

43. Colom LV, Alexianu ME, Mosier DR, et al. Amyotrophic lateral sclerosis immunoglobulins increase intracellular calcium in a motoneuron cell line. Exp Neurol. 1997; 146: 354-360.

44. Siklós L, Engelhardt J, Harati Y, et al. Ultrastructural evidence for altered calcium in motor nerve terminals in amyotrophic lateral sclerosis. Ann Neurol. 1996; 39: 203-216.

45. Siklós L, Engelhardt JI, Alexianu ME, et al. Intracellular calcium parallels motoneuron degeneration in SOD1 mutant mice. J Neuropathol Exp Neurol. 1998; 57: 571-587.

46. Swash M, Meininger V, Swash M. Clinical features and diagnosis of amyotrophic lateral sclerosis In Brown Jr RH (eds.) Amyotrophic Lateral Sclerosis. Sao Paulo Maldem Winnipeg Martin Dunitz. 2000. p. 3-30.

47. Lewit-Bentley A, Réty S. EF-hand calcium-binding proteins. Curr Op Struct Biol. 2000; 10: 637-643.

48. Alexianu ME, Ho BK, Mohamed $\mathrm{H}$, et al. The role of calcium binding proteins in selective motoneuron vulnerability in amyotrophic lateral sclerosis. Ann Neurol. 1994; 36: 846-858.

49. Ho BK, Alexianu ME, Colom LV, et al. Expression of calbindin-D28k in motoneuron hybrid cells after retroviral infection with calbindinD28k cDNA prevents amyotrophic lateral sclerosis IgG-mediated cytotoxicity. Proc Natl Acad Sci USA. 1996; 93: 6796-6801.

50. Dekkers J, Bayley P, Dick JR, et al. Over-expression of parvalbumin in transgenic mice rescues motoneurons from injury-induced cell death. Neuroscience. 2004; 123: 459-466.

51. Paizs M, Engelhardt JI, Katarova Z, et al. Hypoglossal motor neurons display a reduced calcium increase after axotomy in mice with upregulated parvalbumin. J Comp Neurol. 2010; 519: 1946-1961.

52. Beers DR, Ho BK, Siklós L, et al. Parvalbumin overexpression alters immune-mediated increases in intracellular calcium and delays disease onset in a transgenic model of familial amyotrophic lateral sclerosis. J Neurochem. 2001; 79: 499-509.

53. Paizs $\mathrm{M}$, Tortarolo $\mathrm{M}$, Bendotti $\mathrm{C}$, et al. Talampanel reduces the level of motoneuronal calcium in transgenic mutant SOD1 mice only if applied presymptomatically. Amyotroph Lat Sclr. 2011; 12: 340-344.

54. Irwin CW, Kim RB, Mitchell CS. Seeking homeostasis: temporal trends in respiration oxidation and calcium in SOD1 G93A amyotrophic lateral sclerosis mice. Front Cell Neurosci. 2015; 9: Article248. 